\title{
Cambios anatómicos en raíces e hipocótilos de plántulas de Prosopis ruscifolia (Fabaceae) sometidas a estrés salino
}

\author{
Sandra Bravo ${ }^{1}$, Marta Pece ${ }^{2}$, Florencia del Corro ${ }^{1}$, Fernando Ojeda ${ }^{1} \&$ Martín Lepiscopo $^{1}$ \\ 1. Cátedra de Botánica General, Facultad de Ciencias Forestales, Universidad Nacional de Santiago del Estero, \\ Argentina. Avenida Belgrano 1912 (S), Santiago del Estero. Código Postal: 4200; sandrabrav@gmail.com, \\ florenciadelcorro@gmail.com, fernandobrozovich@gmail.com, lepi.ml@gmail.com \\ 2. Cátedra de Estadística, Facultad de Ciencias Forestales, Universidad Nacional de Santiago del Estero, Argentina. \\ Avenida Belgrano 1912 (S), Santiago del Estero. Código Postal: 4200; mpece24@gmail.com
}

\author{
Recibido 11-IX-2015. C Corregido 07-III-2016. Aceptado 07-IV-2016.
}

\begin{abstract}
Anatomical changes in roots and hypocotyls of Prosopis ruscifolia (Fabaceae) seedlings exposed to saline stress. Prosopis ruscifolia is a pioneer tree species in flooding or saline areas. The aim of this work was to assess anatomical changes in roots and hypocotyls of $P$. ruscifolia seedlings induced to saline stress under controlled conditions. Seeds, collected in natural forests of Western Chaco region in Argentina, were sown on paper towels moisturized with saline solutions of 100,200 and $300 \mathrm{mM}$ of $\mathrm{NaCl}$, and a control group with distilled water. Four repetitions of 50 seeds per treatment were sown, located in hermetic polystyrene boxes, and included in a seeding chamber, at $27^{\circ} \mathrm{C}$ and 12 hours photoperiod. Were studied 35 seedlings from each saline concentration; these seedlings were processed 12 days after sown to obtain microscopic samples. The anatomical variables measured in roots and hypocotyls were the following: main root diameter $(\mu \mathrm{m})$, bark thickness $(\mu \mathrm{m})$, number of cell strata in bark, central cylinder diameter $(\mu \mathrm{m})$, pith diameter $(\mu \mathrm{m})$, number of cell strata in the pericycle and the tangential diameter of vessels $(\mu \mathrm{m})$. ANOVA analysis were performed with hypocotyl and root diameters as the dependent variable, and bark thickness $(\mu \mathrm{m})$, number of cell strata in the bark, the central cylinder diameter $(\mu \mathrm{m})$, the pith diameter $(\mu \mathrm{m})$, number of cell strata in the pericycle, the tangential diameter of vessels and the saline concentration as independent variables. Results showed that the root diameter decreased with increasing saline concentrations $(\mathrm{P}<0.0001)$. The bark thickness decreased at $100 \mathrm{mM}(\mathrm{P}<0.0001)$ and the number of cell strata of bark increased to $300 \mathrm{mM}(\mathrm{P}<0.0002)$. The central cylinder diameter decreased at $100 \mathrm{mM}$ saline concentration $(\mathrm{P}<0.0001)$ and the number of cell strata of the pericycle and the pith diameter reduced progressively until $300 \mathrm{mM}$. The tangential diameter of vessels decreased at $300 \mathrm{mM}$. These anatomical changes suggested alterations in the expansion and cell division caused by the salinity, and could limit lateral roots formation and reserves storage. Hypocotyls did not show significant anatomical changes in response to increasing salinity, with exception of stomata position and an increase of the hypodermis thickness. These changes indicated that the water stress imposed by low osmotic potential is caused by increasing saline concentration. The seedlings of $P$. ruscifolia experienced anatomical changes in response to tested saline concentrations in traits related to reserve storage, the absorption and conduction of water, and lateral roots formation. Rev. Biol. Trop. 64 (3): 1007-1017. Epub 2016 September 01.
\end{abstract}

Key words: salinity tolerance, trees, seedlings, Prosopis ruscifolia, semiarid Chaco region.

Prosopis ruscifolia Griseb. (Fabaceae), conocido como vinal, es una especie endémica de la Región Chaqueña argentina, que se distribuye naturalmente en áreas inundables adyacentes a los ríos Dulce y Salado. Es una especie colonizadora y presenta una gran variedad de ecotipos, desde formas arbustivas hasta árboles de $16 \mathrm{~m}$ de altura. En Argentina, para el año 2000 se estimó que existían en unas 2000000 has de vinalares y algunos antecedentes revelan su capacidad de producir madera de calidad y permitir el desarrollo de la actividad ganadera, 
con una buena producción de pasturas bajo su cubierta (Adámoli et al., 2001; Giménez, Ríos, Hernández, \& Moglia, 2009).

El éxito de $P$. ruscifolia como especie colonizadora en ambientes salinos radica en la tolerancia a la salinidad y una vigorosa tasa de crecimiento durante los primeros años de establecimiento, lo que la convierte en una especie promisoria desde el punto de vista productivo. El estadio de plántula corresponde a uno de los más sensibles a las condiciones del medio físico. Por tanto, la tolerancia a la salinidad en este estadio es un requisito indispensable para establecer y mantener poblaciones en ambientes salinos (Casenave, Degano, Toselli, \& Catán, 1999). Entre las adaptaciones fisiológicas al estrés salino se destaca el ajuste osmótico, que consiste en la síntesis de solutos osmocompatibles (azúcares solubles, prolina, glicinbetaína, entre otros) que les permiten disminuir el potencial hídrico de la planta, mantener el gradiente con respecto al suelo y absorber agua aún en presencia de bajos potenciales hídricos (Meloni \& Martínez, 2009; Taleisnick \& López-Launstein, 2011). El ajuste osmótico en plántulas de $P$. ruscifolia sometidas a estrés salino con $\mathrm{NaCl}$ y $\mathrm{SO}_{4} \mathrm{Na}$ ocurre mediante la síntesis de solutos osmocompatibles, como prolina y glicinbetaína (Meloni, 2014).

Sin embargo, en estudios previos se ha reportado que la salinidad induce cambios anatómicos en especies herbáceas y leñosas, que permiten adaptar los procesos fisiológicos a las condiciones de estrés (Casenave et al., 1999; Degano, 1999; Reinoso, Sosa, Ramírez, \& Luna, 2004). Estos cambios involucran el diámetro de las raíces jóvenes, el espesor y número de estratos de células de la corteza, del diámetro del cilindro central, junto a la actividad temprana del periciclo (Casenave et al., 1999; Degano, 1999; Reinoso et al., 2004). Algunas de estas modificaciones han sido atribuidas a alteraciones en los procesos de división, expansión y diferenciación celular, y otros a la necesidad de explorar un mayor volumen de suelo debido al estrés hídrico impuesto por la salinidad (Carillo, Annunziata, Pontecorvo, Fuggi, \& Woodrow, 2011). Los cambios en la anatomía de las plántulas en respuesta al estrés salino permitirían identificar umbrales de tolerancia y las funciones que podrían verse comprometidas en presencia de estrés.

El objetivo del presente trabajo es determinar cambios anatómicos en raíces e hipocótilos de plántulas de $P$. ruscifolia sometidas a estrés salino, en condiciones de laboratorio. Este tipo de estudios podrían contribuir a la interpretación de datos obtenidos a partir de experimentos fisiológicos, y se espera que brinden claridad al momento de analizar el establecimiento de las plántulas de esta especie en condiciones de campo.

\section{MATERIALES Y MÉTODOS}

Sitio de estudio: Se emplearon para estos ensayos semillas cosechadas durante los meses de diciembre a enero de 2008, en la Localidad de Maco, Departamento Capital, en la Provincia de Santiago del Estero, Argentina. El área está incluida en la Región Chaqueña semiárida

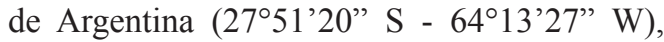
caracterizada por un clima semiárido estacional (Boletta, Ravelo, Planchuelo, \& Grilli, 2006). En esta región, P. ruscifolia forma bosques secundarios (vinalares), que se distribuyen naturalmente en áreas inundables de los ríos Dulce y Salado, y en los márgenes de salitrales. Los suelos se originan en limos loessoides, son salino-sódicos, con mayor proporción de cloruros y sulfatos de sodio (Galizzi, Angueira, \& Prieto, 1999).

Las semillas se obtuvieron de frutos cosechados de árboles maduros, seleccionados al azar en un bosque de $P$. ruscifolia desarrollado al margen de lagunas temporales, distantes a 4 $\mathrm{km}$ de la ciudad capital, Provincia de Santiago del Estero. Los frutos se almacenaron en enfriador a $10^{\circ} \mathrm{C}$, hasta la extracción manual de las semillas. Los ensayos se realizaron dos meses después de extraídas las semillas, que se mantuvieron en congelador a $-17^{\circ} \mathrm{C}$, para evitar el ataque de patógenos (Argañaraz, Abdala, \& Meloni, 2007). Previo a la siembra, las semillas se escarificaron con ácido sulfúrico durante 10 minutos y se enjuagaron con agua 
corriente durante 30 minutos según Bravo, Abdala, Abraham y Pece (2011). La siembra de semillas se realizó sobre toallas de papel tipo Valot siguiendo ISTA (1996). Se sembraron 4 lotes de 50 semillas cada uno, humedecidos con $20 \mathrm{~mL}$ de solución de $\mathrm{NaCl}$ en concentraciones de $0,100,200$ y $300 \mathrm{mM}$ y la concentración cero correspondió al lote de igual número de semillas, humedecidas con agua destilada. El material se dispuso en recipientes plásticos herméticos dentro de una cámara de siembra por un lapso de 12 días a $27^{\circ} \mathrm{C}$ y con 12 horas de fotoperíodo. Las toallas de papel se renovaron a los cinco días de la siembra, para compensar las variaciones en la concentración salina, como consecuencia de la imbibición de las semillas (Bravo et al., 2011).

Las plántulas se extrajeron del sustrato para su estudio 12 días luego de la siembra, y se fijaron en FAA (formol, ácido acético glacial, etanol $96^{\circ}$ y agua destilada), de acuerdo a Reinoso et al. (2004). Se analizaron 35 plántulas para cada tratamiento. Los cortes histológicos de raíces e hipocótilos se realizaron a mano alzada. El teñido y montaje de las muestras se hizo de acuerdo con normas internacionales (Johansen, 1940; D’Ambrogio de Argueso, 1986). Las observaciones se realizaron en 35 plántulas por tratamiento. Se determinó el número de estratos celulares en la corteza y el periciclo. Se midieron el diámetro de raíz e hipocótilos $(\mu \mathrm{m})$, el espesor de la hipodermis $(\mu \mathrm{m})$, el espesor de la corteza $(\mu \mathrm{m})$, el diámetro del cilindro central $(\mu \mathrm{m})$ y el diámetro de la médula $(\mu \mathrm{m})$. Se midió además el diámetro tangencial de vasos del xilema en raíces, como un indicador del efecto del estrés salino sobre la expansión celular y la eficiencia en el transporte de agua. La selección del carácter diámetro de la raíz e hipocótilo se basó en la representatividad del mismo en el tamaño del sistema radical y de la estructura aérea de plántulas y, teniendo en cuenta antecedentes que indican que éste es una de las dimensiones que se modifican significativamente con el estrés salino (Casenave et al., 1999; Reinoso et al., 2004). La medición de los rasgos anatómicos se realizó empleando un microscopio y cámara
Motic, con el Software Motic. 2.0 y se expresaron en micrómetros $(\mu \mathrm{m})$.

Los datos se analizaron con ANOVA con el diámetro, como variable dependiente, y espesor de la hipodermis $(\mu \mathrm{m})$, espesor de la corteza $(\mu \mathrm{m})$, número de estratos celulares en la corte$\mathrm{za}$, diámetro del cilindro central $(\mu \mathrm{m})$, diámetro de la médula $(\mu \mathrm{m})$, número de estratos celulares en el periciclo y concentración salina como variables independientes. El test de Tuckey se usó para la separación de medias. Los datos de espesor de corteza y diámetro de cilindro central se transformaron a $\ln$ por falta de homogeneidad de las varianzas y por tratarse de variables continuas. En estos casos se empleó el test no paramétrico de Kruskal Wallis. Se utilizó el paquete estadístico INFOSTAT.

\section{RESULTADOS}

Las plántulas de $P$. ruscifolia que se desarrollaron en condiciones de control presentaron externamente morfología normal. La presencia de raíces laterales, tanto en el control como en los demás tratamientos, ha sido poco frecuente, al menos en los días de duración de los ensayos. Las plántulas de $P$. ruscifolia presentaron raíces embrionales tetrarcas (Fig. 1 A), con rizodermis unistrata, una hipodermis pluriestrata colenquimatosa, con algunos espacios intercelulares. Las células corticales son isodiamétricas, con las de mayor tamaño en el sector medio de la corteza y escasos espacios intercelulares poligonales (Fig. 1 B y Fig. C). $\mathrm{La}$ endodermis presenta engrosamientos puntuales en las paredes radiales, con células de mayor tamaño que las del periciclo. El cilindro central se observa perfectamente definido (Fig. 1 B). El periciclo mostró una actividad temprana, con áreas de activa división celular cerca de los polos protoxilemáticos (Fig. 1 D). Los polos xilemáticos se observan definidos, con abundantes vasos, alternando con polos de floema, que presentan casquetes de fibras floemáticas, resultando la estructura típica de raíces de dicotiledóneas, (Fig. 1 A). La médula es parenquimática, con abundantes corpúsculos semejantes a gránulos de almidón. 

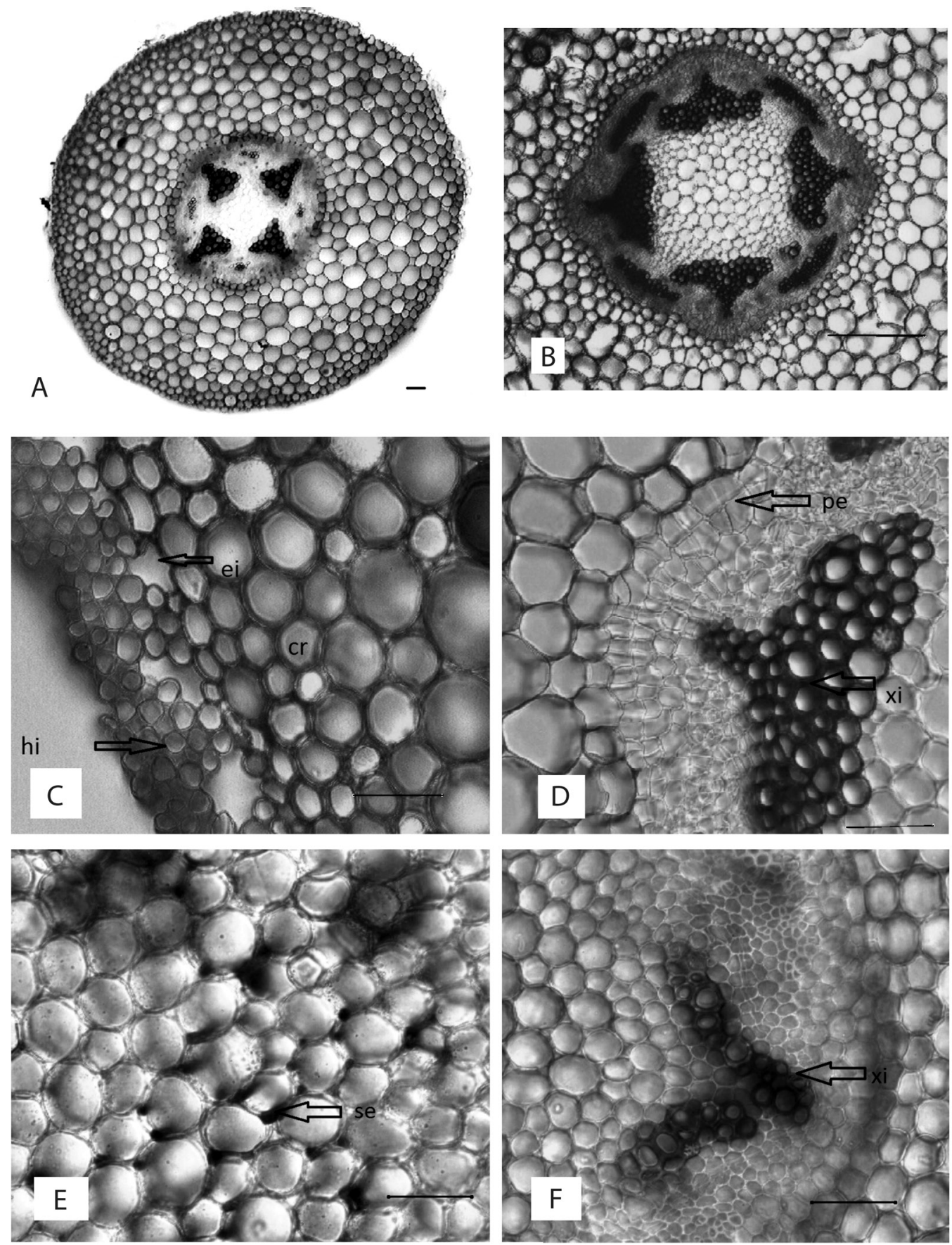

Fig. 1. Secciones transversales de raíces de plántulas de Prosopis ruscifolia. A, B, C y D. Plántulas control. A. vista general. B- detalle de cilindro central. C- detalle de hipodermis con espacios intercelulares. D- detalle de periciclo frente al polo protoxilemático. E y F- plántula a $200 \mathrm{mM}$ de $\mathrm{NaCl}$. E- productos de secreción en espacios intercelulares de la corteza. F- reducción del polo de protoxilema. Barra de la escala $=50 \mu \mathrm{m}$. hi: hipodermis, ei: espacio intercelular, cr: corteza, pe: periciclo, xi: polo de xilema, se: productos de secreción. 
A mayores concentraciones salinas $(200$ y $300 \mathrm{mM}$ ) se observó un mayor número de plántulas con raíces anormales, retorcidas y con manchas pardo-oscuras sobre los hipocótilos. El cuadro 1 muestra los valores promedio y desvíos estándar del diámetro de las raíces, del cilindro central y la médula, del espesor de la hipodermis y la corteza, número de estratos celulares en la corteza y el periciclo y diámetro tangencial de los vasos de polo de xilema, en plántulas control y en las sometidas a salinidad creciente. El diámetro de las raíces de $P$. ruscifolia decreció significativamente con el aumento de la concentración de $\mathrm{NaCl}$, debido a cambios en el espesor de la corteza y del diámetro del cilindro central $(\mathrm{P}<0.0001$; Cuadro 1). El espesor de la hipodermis no evidenció cambios significativos al incrementar la concentración salina (Cuadro 1). El diámetro promedio de las raíces de las plántulas sometidas a la concentración salina de $100 \mathrm{mM}$ se redujo significativamente respecto de las plántulas control; mientras aquellas crecidas a 200 y $300 \mathrm{mM}$ no evidenciaron diferencias significativas entre ellas, pero sí respecto del control. El espesor de la corteza se redujo a $100 \mathrm{mM}$, mientras que el número de estratos celulares que la componen aumentó significativamente a $300 \mathrm{mM}(\mathrm{P}<0.0002)$. El diámetro promedio del cilindro central se redujo al aumentar la concentración salina en el medio de siembra $(\mathrm{P}<0.0001)$, observándose también disminución del diámetro de la médula, del número de estratos celulares del periciclo y del diámetro tangencial de los vasos en los polos de xilema $(\mathrm{P}<0.0001)$ (Cuadro 1, Fig. 1 F). La actividad temprana del periciclo se observó aún con concentraciones de $300 \mathrm{mM}$. Al emplearse mayores concentraciones salinas se depositaron compuestos oscuros en espacios intercelulares de la médula, cuya naturaleza bioquímica no fue confirmada en el presente trabajo (Fig. 1 E).

El hipocótilo de plántulas de $P$. ruscifolia se presenta externamente costillado (Fig. 2 A, Fig. 2B, Fig. 2C) y las costillas coinciden con proyecciones de la epidermis e hipodermis, donde se localizan estomas (Fig. 2C). La epidermis es unistrata, sin tricomas, al menos hasta el estadio de desarrollo de las plántulas estudiadas (12 días desde la siembra, Fig. 2 A), presenta una hipodermis de 2 ó 3 estratos, con grandes espacios intercelulares, limitada por una banda de células colenquimáticas, comprimidas en sentido tangencial (Fig. 2 A, Fig. 2B). La corteza es parenquimática, de menor desarrollo que la corteza radical, con células isodiamétricas (Fig. 2 A, Fig. 2C, Fig. 2E, Fig. 2F), iguales al parénquima medular (Fig. 2 D),

CUADRO 1

Variables anatómicas de las raíces de plántulas de Prosopis ruscifolia, cultivadas con soluciones de 0 (control), 100, 200 y $300 \mathrm{mM}$ de $\mathrm{NaCl}$

TABLE 1

Anatomical variables of roots of Prosopis ruscifolia seedlings, sown with solutions of 0 (control), 100,200 y $300 \mathrm{mM}$ de $\mathrm{NaCl}$

\begin{tabular}{lcccc}
\multicolumn{1}{c}{ Variable } & Control & $100 \mathrm{mM}$ & $200 \mathrm{mM}$ & $300 \mathrm{mM}$ \\
Diámetro total $(\mu \mathrm{m})$ & $1650.0 \pm 147.2 \mathrm{a}$ & $1314.3 \pm 199.7 \mathrm{~b}$ & $1490.5 \pm 234.4 \mathrm{c}$ & $1500.0 \pm 182.4 \mathrm{c}$ \\
Espesor de hipodermis $(\mu \mathrm{m})$ & $67.3 \pm 13.6 \mathrm{a}$ & $59.50 \pm 15.4 \mathrm{a}$ & $62.33 \pm 23.0 \mathrm{a}$ & $64.17 \pm 21.3 \mathrm{a}$ \\
Espesor de corteza $(\mu \mathrm{m})$ & $458.7 \pm 72.7 \mathrm{a}$ & $368.57 \pm 75.6 \mathrm{~b}$ & $444.6 \pm 107.7 \mathrm{a}$ & $432.86 \pm 79.3 \mathrm{a}$ \\
Número de estratos celulares de corteza & $13.5 \pm 1.9 \mathrm{a}$ & $12.74 \pm 2.4 \mathrm{a}$ & $14.00 \pm 2.4 \mathrm{a}$ & $15.17 \pm 2.35 \mathrm{~b}$ \\
Diámetro de cilindro central $(\mu \mathrm{m})$ & $588.7 \pm 52.7 \mathrm{a}$ & $458.00 \pm 41.1 \mathrm{~b}$ & $486.22 \pm 73.3 \mathrm{c}$ & $510.57 \pm 59.7 \mathrm{c}$ \\
Diámetro de médula $(\mu \mathrm{m})$ & $325.5 \pm 47.7 \mathrm{a}$ & $246.86 \pm 34.1 \mathrm{~b}$ & $254.59 \pm 48.1 \mathrm{~b}$ & $264.29 \pm 56.1 \mathrm{~b}$ \\
Número de estratos celulares del periciclo & $3.0 \pm 1.3 \mathrm{a}$ & $2.22 \pm 1.4 \mathrm{~b}$ & $2.22 \pm 1.2 \mathrm{~b}$ & $1.71 \pm 0.9 \mathrm{~b}$ \\
Diámetro tangencial de vasos $(\mu \mathrm{m})$ & $17.2 \pm 3.6 \mathrm{a}$ & $15.78 \pm 2.2 \mathrm{a}$ & $15.34 \pm 3.3 \mathrm{a}$ & $13.79 \pm 1.7 \mathrm{~b}$ \\
\hline
\end{tabular}

En la misma fila, letras diferentes indican diferencias significativas $(\mathrm{P}<0.05)$.

Different letters in a same row indicate significant differences $(\mathrm{P}<0.05)$. 

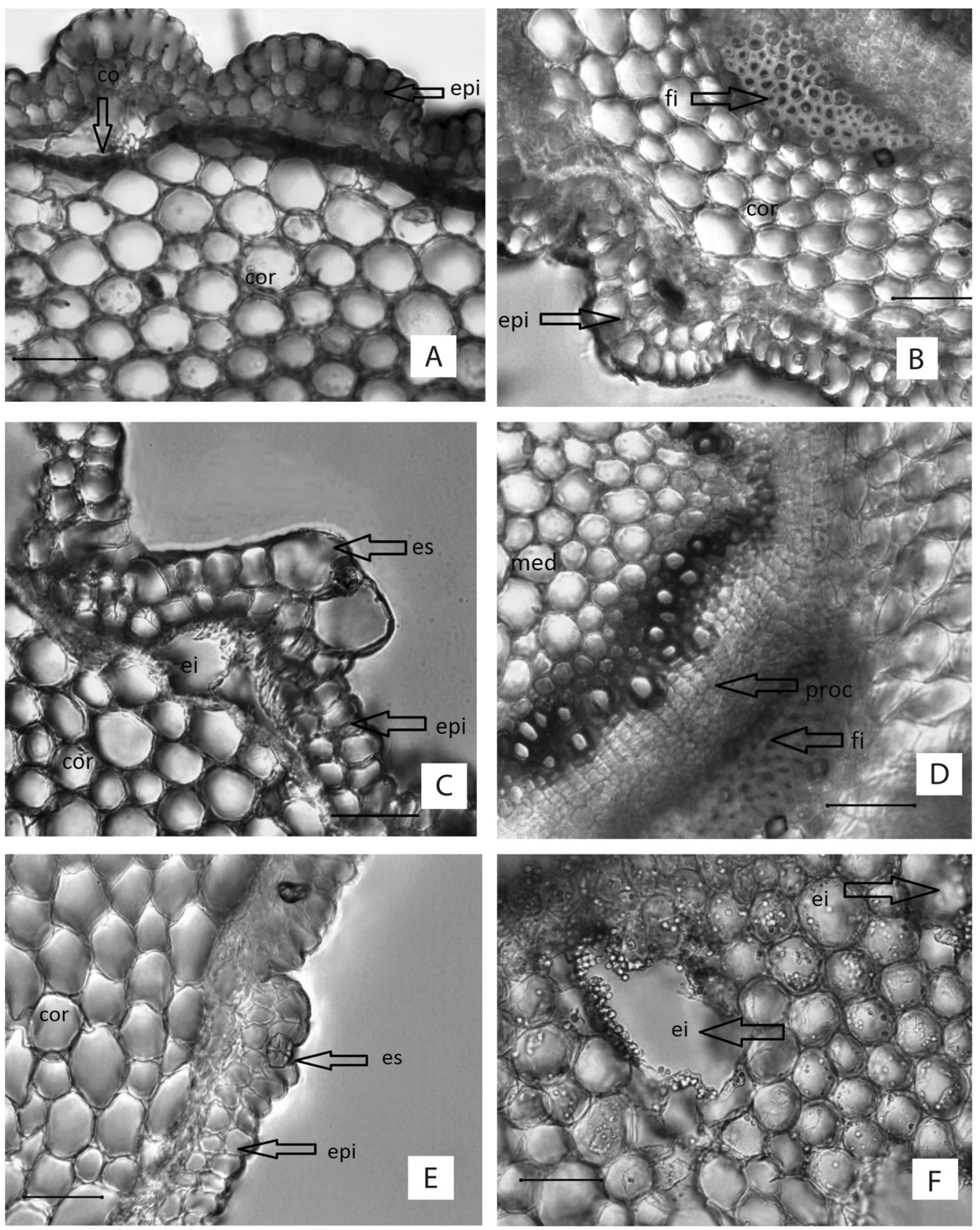

Fig. 2. Secciones transversales de hipocótilos en plántulas de Prosopis ruscifolia. A, B, C y D- plántulas control. Aepidermis, hipodermis y corteza B- epidermis, corteza y fibras. C- epidermis con estomas elevados en costillas (100 mM). D- detalle de haz vascular. E- detalle de epidermis con estomas hundidos $(200 \mathrm{mM})$. F- detalle de corteza con espacios intercelulares $(300 \mathrm{mM})$. Barra de la escala $=50 \mu$. epi: epidermis, es: estoma, ei: espacio intercelular, co: colénquima, cor: corteza, fi: fibras y proc: procámbium. 
con abundantes corpúsculos semejantes a amiloplastos (Fig. 2 F). En el estadio de desarrollo de las plántulas estudiadas, los haces vasculares se observan diferenciados (Fig. 2 D), con la banda procambial compuesta por varios estratos, en clara señal de actividad histogénica. El floema primario presenta en su cara externa un casquete de fibras. En el cuadro 2 se muestran los valores promedio y desvíos estándar de diámetro total de hipocótilos, espesor de la hipodermis y de la corteza, número de estratos celulares en la corteza, diámetro del cilindro central (considerando como tal el anillo delimitado por la disposición de los haces) y de médula, en plántulas control y en las sometidas a salinidad creciente.

La mayor parte de las variables anatómicas medidas en hipocótilos de plántulas de vinal no experimentaron cambios significativos con el incremento de la salinidad en el medio de cultivo (Cuadro 2). Sin embargo, la epidermis e hipodermis evidenciaron cambios cuali y cuantitativos. Las plántulas control y las sometidas a la concentración de $100 \mathrm{mM}$ mostraron células epidérmicas con estomas elevados a nivel de las costillas y espacios intercelulares asociados a ellos (Fig. 2 C). La hipodermis incrementó significativamente su espesor a 100 y $200 \mathrm{mM}$ $(\mathrm{P}<0.004)$, desaparecieron los espacios intercelulares y los estomas se observaron hundidos en la epidermis (Fig. 2 E). A una concentración de $300 \mathrm{mM}$ la hipodermis aumentó su espesor notablemente y se desprendió fácilmente de las muestras al hacer los cortes histológicos. Por esta razón, sólo se analizó el efecto de los tratamientos a 100 y $200 \mathrm{mM}$. No hubo cambios estadísticamente significativos en el espesor ni el número de estratos celulares de la corteza al incrementar la concentración salina. En la corteza se observaron abundantes corpúsculos semejantes a amiloplastos y espacios celulares, algunos de gran tamaño, sin productos de secreción (Fig. 2F).

\section{DISCUSIÓN}

Los cambios observados en las raíces de plántulas de $P$. ruscifolia coinciden, en líneas generales, con los observados por Reinoso et al. (2004) en P. strombulifera. La ausencia de diferencias significativas en el espesor de la hipodermis de raíces al aumentar la concentración salina, y el grosor de las paredes de las células que la componen, sugieren una función más bien mecánica que fisiológica. Las hipodermis colenquimatosas contienen elevadas concentraciones de pectinas y hemicelulosas, que contribuyen con el soporte, además de la protección contra patógenos (Mauseth, 2006; Loza-Cornejo \& Terrazas, 2011). La significativa reducción del diámetro de las raíces de plántulas de $P$. ruscifolia, acompañada de

CUADRO 2

Variables anatómicas de hipocótilos de plántulas de Prosopis ruscifolia, cultivadas en soluciones conteniendo 0 (control), 100, 200 y $300 \mathrm{Mm}$ de $\mathrm{NaCl}$

TABLE 2

Anatomical variables of hypocotyls of Prosopis ruscifolia seedlings, sown with solutions of 0 (control), 100, 200 y $300 \mathrm{mM}$ de $\mathrm{NaCl}$

\begin{tabular}{lcccc}
\multicolumn{1}{c}{ Variable } & Control & $100 \mathrm{mM}$ & $200 \mathrm{mM}$ & $300 \mathrm{mM}$ \\
Diámetro total $(\mu \mathrm{m})$ & $1200.7 \pm 181.8 \mathrm{a}$ & $1160.0 \pm 206.9 \mathrm{a}$ & $1221.4 \pm 137.3 \mathrm{a}$ & $1211.4 \pm 126.6 \mathrm{a}$ \\
Espesor de hipodermis $(\mu \mathrm{m})$ & $77.14 \pm 28.9 \mathrm{a}$ & $104.43 \pm 38.9 \mathrm{~b}$ & $109.5 \pm 37.5 \mathrm{~b}$ & - \\
Espesor de corteza $(\mu \mathrm{m})$ & $282.00 \pm 73.8 \mathrm{a}$ & $282.86 \pm 83.6 \mathrm{a}$ & $299.1 \pm 72.1 \mathrm{a}$ & $312.0 \pm 57.3 \mathrm{a}$ \\
Número de estratos celulares de corteza & $10.6 \pm 2.2 \mathrm{a}$ & $10.3 \pm 1.9 \mathrm{a}$ & $10.7 \pm 2.6 \mathrm{a}$ & $11.2 \pm 1.9 \mathrm{a}$ \\
Diámetro de cilindro central $(\mu \mathrm{m})$ & $605.14 \pm 91.1 \mathrm{a}$ & $608.57 \pm 95.9 \mathrm{a}$ & $581.7 \pm 92.4 \mathrm{a}$ & $530.9 \pm 54.6 \mathrm{a}$ \\
Diámetro de médula $(\mu \mathrm{m})$ & $410.00 \pm 54.3 \mathrm{a}$ & $400.29 \pm 79.8 \mathrm{a}$ & $420.0 \pm 82.1 \mathrm{a}$ & $458.3 \pm 151.7 \mathrm{a}$ \\
\hline
\end{tabular}

En la misma fila, letras diferentes indican diferencias significativas $(\mathrm{P}<0.05)$.

Different letters in a same row indicate significant differences $(\mathrm{P}<0.05)$. 
la disminución del espesor y el aumento del número de estratos celulares de corteza (300 $\mathrm{mM}$ ), sugiere el efecto del estrés osmótico y la alteración de la expansión celular. La reducción en la expansión y división celular han sido descritas como alteraciones comunes en plantas sometidas a estrés salino (Munns, 2002; Zhu, 2007). Carillo et al. (2011) consideran que el efecto osmótico de las sales se manifiesta inmediatamente después de la exposición y que continúa hasta la inhibición de la expansión y división celular.

La reducción del diámetro del cilindro central, del diámetro de la médula y diámetro tangencial de vasos en el xilema de raíces de plántulas de $P$. ruscifolia, son manifestaciones también de la limitación impuesta por el estrés osmótico sobre la expansión celular. Sin embargo, la disminución del número de estratos del periciclo, observada a $300 \mathrm{mM}$ de $\mathrm{NaCl}$, podría representar también una alteración del proceso de división celular. Según Chinnusamy, Jagendorf y Zhu (2005), los cambios observados a baja concentración salina parecen estar relacionados con la toxicidad de los iones, mientras que los cambios generados por mayores concentraciones podrían ser atribuidos a estrés osmótico. La actividad temprana del periciclo ha sido citada para otras especies de Prosopis (Reinoso et al., 2004) y vinculada a la formación de raíces laterales para aumentar el volumen de exploración en suelo. La reducción en el número de estratos del periciclo, en raíces de plántulas de $P$. ruscifolia sometidas a estrés salino podría comprometer la producción de raíces laterales y limitar la exploración de un mayor volumen de suelo, lo cual es una ventaja esencial para el establecimiento en suelos salinos (Meloni, 2014).

Casenave et al. (1999) describieron una reducción en el espesor de corteza y un incremento en el diámetro de la médula, en radículas de Gossypium hirsutum L. sometidas a estrés salino de $275 \mathrm{mM}$ de $\mathrm{NaCl}$. En plántulas de $P$. ruscifolia se observó reducción significativa del cilindro central, del diámetro de la médula, del tamaño de los polos del xilema y del diámetro tangencial de vasos al incrementar la salinidad (300 Mm), lo que podría originar cierta dificultad en la conducción de agua hacia la parte aérea. En P. strombulifera se ha observado también, disminución de diámetro tangencial de los vasos por efecto de la salinidad a partir de $500 \mathrm{mM}$, en plántulas de 53 a 77 días (Reinoso et al., 2004). Boughalleb, Hajlaoui y Denden (2012) determinaron en raíces de algodón alteraciones en la actividad cambial en respuesta a la salinidad y vasos de menor diámetro, sugiriendo una función adaptativa para asegurar el flujo de agua, debido al menor riesgo de embolia.

La presencia de productos de secreción en espacios intercelulares del parénquima de la médula radical concuerda con los resultados obtenidos por Meloni, Gulotta y Oliva-Cano (2008), quienes demostraron la presencia y aumento de las concentraciones de polifenoles en todos los tejidos de plántulas de vinal, sometidas a estrés salino. Numerosos estudios sugieren que los taninos y polifenoles se acumulan en respuesta a condiciones de estrés, y pueden tener una función de protección. Reinoso et al. (2004) comunicaron que la $\mathrm{NaCl}$ estimuló la secreción de taninos en tallos y hojas de plántulas de $P$. strombulifera sometidas a estrés salino. Estos antecedentes podrían indicar la naturaleza fenólica de las sustancias acumuladas en espacios intercelulares de médula radical, en el presente estudio.

De acuerdo con nuestros resultados, la salinidad afecta el tejido cortical y el cilindro central de raíces de plántulas de $P$. ruscifolia a partir de $100 \mathrm{mM}$, lo que podría reducir la eficiencia en el almacenamiento de reservas, en la conducción de agua hacia la parte aérea y limitar la formación de raíces laterales. Reinoso et al. (2004) observaron una limitación del crecimiento de plántulas de $P$. strombulifera por encima de $450 \mathrm{mM}$. Sin embargo, los cambios observados en plántulas de $P$. ruscifolia a $300 \mathrm{mM}$ de $\mathrm{NaCl}$ indicaría una respuesta anatómica a la concentración salina creciente, probablemente ajustada a mecanismos fisiológicos, que les permitiría establecerse en ambientes de características semejantes. 
El incremento de salinidad no produjo cambios significativos en las variables analizadas en hipocótilos de plántulas de $P$. ruscifolia, con excepción del aumento en el espesor de la hipodermis y la presencia de espacios intercelulares en la corteza. Reinoso et al. (2004) determinaron una reducción del diámetro y grado de lignificación de los tejidos de hipocótilos de $P$. strombulifera al incrementarse la concentración salina de 250-700 mM. Degenhardt y Gimmler (2000) y Gomes et al. (2011; citados por Atabayeva et al. (2013), comunicaron un incremento en el espesor y la lignificación de la exodermis y del número de espacios intercelulares en corteza en Brachiaria decumbens Stapf, causado por el aumento en la salinidad. El agrandamiento de las células epidérmicas, con estomas elevados sobre el nivel de las restantes células, en hipocótilos de plántulas control y de las expuestas a $100 \mathrm{mM}$ (Fig. 2 A, Fig. 2C) se ha observado también en epidermis foliares de Zea mays L. a idéntica concentración salina (Carcamo, Bustos, Fernández, \& Bastias, 2012). El cambio de posición de estomas al aumentar la concentración salina parece reflejar el incremento en estrés hídrico impuesto por la salinidad, ya que estomas hundidos son característicos de especies de ambientes áridos y semiáridos. Nuestros resultados evidencian que las plántulas de $P$. ruscifolia, modifican algunos rasgos anatómicos en respuesta al estrés salino, como ha sido observado por Munns (2002), Reinoso et al. (2004) y Carrillo et al. (2011) en especies herbáceas y leñosas.

Meloni (2014), informó que P. ruscifolia puede desarrollarse en soluciones salinas de hasta $400 \mathrm{mM}$, incrementando la biomasa aérea y radicular de las plántulas con respecto a aquellas creciendo en condiciones de control. Las plántulas de P. ruscifolia en este trabajo, mostraron tolerancia a la salinidad hasta 300 $\mathrm{mM}$ pero experimentaron cambios anatómicos relacionados con estrés salino, siendo los más relevantes, la reducción en diámetro de raíz, del espesor de la corteza y del diámetro del cilindro central, del diámetro de la médula, del diámetro tangencial de los vasos y del número de estratos celulares del periciclo. Estos cambios anatómicos podrían estar relacionados con procesos fisiológicos dificultados por la salinidad, como la expansión y división celular. Los hipocótilos de las plántulas de $P$. ruscifolia no manifiestan cambios anatómicos significativos a nivel de la corteza ni del tejido vascular, pero sí a nivel de la epidermis (estomas hundidos) y de la hipodermis (aumento de espesor). Dichos cambios podrían estar relacionados con el estrés hídrico producido por el bajo potencial osmótico al aumentar la salinidad. El aumento en el espesor de la hipodermis en hipocótilos responde probablemente a una mayor necesidad de sostén, ya que las células son colenquimatosas. Estos cambios sugieren que al aumentar la concentración salina podría dificultarse el almacenamiento de reservas, el ingreso y la conducción de agua y la formación de raíces laterales en plántulas de $P$. ruscifolia. Se recomiendan ensayos para corroborar las posibilidades de establecimiento a campo.

\section{AGRADECIMIENTOS}

Los autores agradecen a la Secretaría de Ciencia y Técnica de la Universidad Nacional de Santiago del Estero, Argentina por la financiación de la presente investigación y al Instituto de Silvicultura y Manejo de Bosques de la Facultad de Ciencias Forestales, por el uso de las instalaciones para los ensayos.

\section{RESUMEN}

Prosopis ruscifolia es una especie arbórea pionera en áreas inundadas o salinas. El objetivo de este trabajo fue determinar cambios anatómicos en raíces e hipocótilos de plántulas de $P$. ruscifolia sometidas a estrés salino, bajo condiciones controladas. Las semillas se recolectaron en bosques nativos de la Región Chaqueña Occidental de Argentina. Las semillas se sembraron sobre toallas de papel humedecidas con soluciones salinas de 100, 200 y $300 \mathrm{mM}$ de $\mathrm{NaCl}$ y un control humedecido con agua destilada. Se sembraron cuatro repeticiones de 50 semillas cada una, correspondientes a cada tratamiento, se ubicaron en cajas plásticas herméticas dentro de cámara de siembra a $27{ }^{\circ} \mathrm{C}$ y con fotoperíodo de 12 horas. Doce días después de la siembra, se extrajeron plántulas para estudios anatómicos. Se estudiaron 35 plántulas correspondientes 
a cada tratamiento. Se midieron en raíces e hipocótilos las siguientes variables anatómicas: diámetro de la raíz principal e hipocótilo $(\mu \mathrm{m})$, espesor de la corteza $(\mu \mathrm{m})$, número de estratos celulares en la corteza, diámetro del cilindro central $(\mu \mathrm{m})$, diámetro de la médula $(\mu \mathrm{m})$, número de estratos celulares en el periciclo y diámetro tangencial de los vasos $(\mu \mathrm{m})$. Se realizó ANOVA con diámetro de la raíz o hipocótilo como variable dependiente y espesor de la corteza, número de estratos celulares en la corteza, diámetro del cilindro central, diámetro de la médula, número de estratos celulares en el periciclo, diámetro tangencial de los vasos y concentración salina como variables independientes. El diámetro de la raíz disminuyó significativamente con el aumento de la concentración salina $(\mathrm{P}<0.0001)$. El espesor de la corteza redujo su espesor a $100 \mathrm{mM}(\mathrm{P}<0.0001)$ e incrementó el número de estratos celulares que la componen $(\mathrm{P}<0.0002)$. El diámetro del cilindro central se redujo a la concentración salina de 100 $\mathrm{mM}(\mathrm{P}<0.0001)$ y el diámetro de la médula y el número de estratos celulares del periciclo $(\mathrm{P}<0.0003)$ disminuyó progresivamente hasta $300 \mathrm{mM}$. El diámetro tangencial de los vasos $(\mathrm{P}<0.0001)$ se redujo recién a $300 \mathrm{mM}$ de $\mathrm{NaCl}$. Estos cambios anatómicos podrían estar relacionados con la alteración de la expansión y división celular causada por la salinidad y comprometer la formación de raíces laterales y el almacenamiento de reservas. Los hipocótilos no mostraron cambios anatómicos significativos en respuesta al incremento en la salinidad, con excepción de la variación en la posición de estomas y un incremento en el espesor de la hipodermis. Estos cambios parecen indicar el estrés hídrico impuesto por el bajo potencial osmótico causado por las sales. Las plántulas de $P$. ruscifolia experimentaron cambios anatómicos en respuesta a las concentraciones salinas analizadas, en rasgos vinculados al almacenamiento de reservas, a la absorción y la conducción de agua y la formación de raíces laterales.

Palabras clave: tolerancia a salinidad, árboles, plántulas, Prosopis, región chaqueña semiárida.

\section{REFERENCIAS}

Adámoli, J., Astrada, E., Blasco, C., Florio, A., Tomasini, D., Martínez Ortiz, U., \& Calonge, P. (2001). Evaluación económica de un modelo de uso silvopastoril de vinalares y su adecuación como instrumento de gestión política. $1^{\circ}$ Congreso Rioplatense de Economía Agraria-XXXI Reunión Anual de Economía Agraria. Montevideo, Uruguay.

Argañaráz, J., Abdala, R., \& Meloni, D. (2007). Efectos del almacenamiento sobre la germinación de semillas de vinal Prosopis ruscifolia Griseb. XIII Jornadas Forestales de Entre Ríos, Argentina.

Atabayeva, S., Nurmahanova, A., Minocha, S., Ahmetova1, A., Kenzhebayeva, S., Aidosova1, S., Nurzhanova, A., Zhardamalieva1, A., Asrandina1, S., Alybayeva1,
R., \& Li, T. (2013). The effect of salinity on growth and anatomical attributes of barley seedling. African Journal of Biotechnology, 12, 2366-2377.

Boletta, P., Ravelo, A., Planchuelo, A., \& Grilli, M. (2006). Assessing deforestation in the Argentine Chaco. Forest Ecology and Management, 228, 108-114.

Boughalleb, F., Hajlaoui, H., \& Denden, M. (2012). Effect of salt stress on growth, water relations, solute composition and photosynthetic capacity of hero-halophyte Nitraria retusa (L.). Environmental Resource Journal, 6(1), 1-13.

Bravo, S., Abdala, R., Abraham, F., \& Pece, M. (2011). Treatments to improve the germination of Prosopis kuntzei Harms, Mimosaceae. Seed Technology Journal, 31(1), 55-62.

Carcamo, H., Bustos, M., Fernández, F., \& Bastias, E. (2012). Mitigating effect of salicylic acid in the anatomy of the leaf of Zea mays L. lluteno ecotype from the Lluta Valley (Arica-Chile) under $\mathrm{NaCl}$ stress. IDESIA, 30(3), 55-63.

Carillo, P., Annunziata, M. G., Pontecorvo, G., Fuggi, A., \& Woodrow, P. (2011). Salinity Stress and Salt Tolerance, Mechanisms and Adaptations. En A. Shanker, \& B. Venkateswarlu, (Eds.), Abiotic Stress in Plants. Agricultural and Biological Sciences (pp, 21-38). Italy.

Casenave, E., Degano, C., Toselli, M., \& Catán, A. (1999). Statistical studies on anatomical modifications in the radicle and hypocotyl of cotton induced by $\mathrm{NaCl}$. Biological Research, 32(4), 1-10.

Chinnusamy, V., Jagendorf, A., \& Zhu, J. (2005). Understanding and improving salt tolerance in plants. Crop Science, 45, 437-448.

D’Ambrogio de Argueso, A. (1986). Manual de Técnicas en Histología Vegetal. Buenos Aires, Argentina: Editorial Hemisferio Sur, S.A.

Degano, C. (1999). Respuestas morfológicas y anatómicas de Tessaria absinthioides (Hook. et Arn.) DC. a la salinidad. Revista Brasileña de Botánica, 22(3), 357-363.

Degenhardt B, \& Gimmler, H. (2000). Cell wall adaptations to multiple environment stresses in maize root. Journal of Experimental Botany, 51, 595-603.

Galizzi, F., Angueira, C., \& Prieto, D. (1999). Suelos de la planta piloto de drenaje del INTA, Santiago del Estero. Quebracho, 7, 52-60.

Giménez, A., Ríos, N., Hernández, P., \& Moglia, J. (2009). Influencia de la edad en el crecimiento de vinal (Prosopis ruscifolia Burkart.), en la Provincia de Santiago del Estero, Argentina. Madera y Bosques, 15(2), 45-57. 
ISTA. (1996). International rules for seed testing. International Seed Testing Association. Zurich.

Johansen, D. H. (1940). Plant microtechnique. New York: McGraw-Hill.

Loza-Cornejo, S. \& Terrazas, T. (2011). Morfo-anatomía de plántulas en especies de Pachycereeae: ¿hasta cuándo son plántulas? Boletín de la Sociedad Botánica Mexicana, 88, 1-13.

Mauseth, J. D. (2006). Structure-function relationships in highly modified shoots of Cactaceae. Annals of Botany, 98, 901-926.

Meloni, D. (2014). Respuestas fisiológicas de plántulas de Prosopis alba sometidas a estrés salino (Tesis Doctoral). Universidad Nacional de Santiago del Estero, Argentina.

Meloni, D., Gulotta, M., \& Oliva-Cano, M. (2008). El estrés salino incrementa la actividad de enzimas antioxidantes y la concentración de polifenoles en vinal (Prosopis ruscifolia G.). Quebracho, 15, 27-31.

Meloni, D., \& Martínez, C. (2009). Glycinebetaine improves salt tolerante in vinal (Prosopis ruscifolia Griesbach) seedlings. Brazilian Journal of Plant Physiology, 21(3), 233-241.

Munns, R. (2002). Comparative physiology of salt and water stress. Plant, Cell \& Environment, 25(2), 239-250.

Reinoso, H., Sosa, L, Ramírez, L., \& Luna, V. (2004). Salt-induced changes in the vegetative anatomy of Prosopis strombulifera (Leguminoseae). Canadian Journal of Botany, 82, 618-628.

Taleisnick, E. \& López Launstein, D. (2011). Especies leñosas en ambientes salinos. Ecología Austral, 21, $3-14$.

Zhu, J. (2007). Plant Salt Stress. John Wiley \& Sons, Ltd. 
